Kamil Krasuski - Stepan Savchuk

\title{
ACGURACY ASSESSMENT OF AIRCRAFT POSITIONING USING THE DUAL-FREQUENCY GPS CODE OBSERVATIONS IN AVIATION
}

This study publishes results of tests with regard to determination of the aircraft positioning accuracy by means of the GPS navigation in aviation. The research exploits the mathematical model of the linear combination "IonosphereFree" in order to designate the coordinates of an aircraft. The research uses the actual GPS code observations, recorded by a satellite receiver mounted in the Cessna 172, at the time of the experiment for the EPDE military aerodrome in Deblin. The computations of the position of the Cessna 172 aircraft for the linear combination "Ionosphere-Free" were made in the APS Toolbox v.1.0.0. programme. Within evaluation of accuracy of the GPS positioning in aviation, the determined coordinates of the aircraft Cessna 172 from the APS programme were compared to an accurate reference position from the solution derived by the PPP measurement technique. In the research, the authors obtained an average positioning accuracy of approximately $5 \mathrm{~m}$ in the geocentric XYZ coordinates and approximately $4 \mathrm{~m}$ in the ellipsoidal BLh coordinates. In addition, the 3D-error parameter is lower than $7 \mathrm{~m}$ for the XYZ geocentric coordinates.

Keywords: GPS, Ionosphere-Free linear combination, accuracy, PPP method, aviation

\section{Introduction}

In the 21st century, the GNSS satellite technology became a common method of aircraft positioning in the field of air navigation and air transport. Development of modern GNSS global navigation systems, such as GPS, GLONASS, BeiDou, Galileo, QZSS Zenith and augmentation systems SBAS (EGNOS, SDCM, WAAS, MSAS, GAGAN, NAVIC) enabled their full operation and implementation in the process of determining the aircraft position. The framework of application, operation and implementation of the GNSS satellite technology in aviation has been clearly defined by the International Civil Aviation Organization (ICAO). The Annex 10 to the Chicago Convention currently allows the use of the GNSS satellite technique in aviation for the needs of performing air operations within the navigation systems of: GPS and GLONASS as GNSS satellite systems which are certified by the ICAO and augmentation systems: ABAS, SBAS, GBAS [1-3].

In the case of the global GNSS navigation systems, only the GPS and GLONASS satellite systems are certified for a general use in civil aviation. It should be emphasized that the GPS and GLONASS systems are fully operational and provide continuous satellite positioning for its users across the globe for 24 hours a day. Certification of the GPS and GLONASS navigation systems in civil aviation includes such parameters as accuracy, availability, reliability and continuity [4]. In accordance with the ICAO recommendation, the accuracy of determining the position of an aircraft with the use of the GPS navigation system must not exceed $17 \mathrm{~m}$ for navigation in the horizontal plane, and $37 \mathrm{~m}$ for navigation in the vertical plane [5]. Furthermore, the time synchronization error in the GPS system during a flight operation must not be worse than $40 \mathrm{~ns}$ (approximately $12 \mathrm{~m}$ ). In addition, error of the GPS satellite's position in the orbit must not be greater than $30 \mathrm{~m}$, whereas an error of determining the GPS satellite speed and acceleration must not exceed values of 0.006 $\mathrm{m} / \mathrm{s}$ and $0.002 \mathrm{~m} / \mathrm{s}^{2}$, respectively. In turn, availability of the constellation of the GPS satellites during the flight operations should exceed 99\%. The credibility parameter of the GPS system functioning in the civil aviation should exceed $99.79 \%$ across the whole globe. The likelihood of the lack of continuity of the navigation solution of an aircraft position by means of the GPS observation must not exceed $2 \cdot 10^{-4}$ per hour [6]. It should be mentioned that the criteria of the parameters of accuracy, availability, reliability and continuity are referenced to the standard SPS positioning service in the GPS navigation system [7]. Within the Standard Positioning Service, it is possible to use L1-C/A observation codes to determine the coordinates of an aircraft in the GPS system. It must be noted that the GPS satellites transmit the signal L1-C/A on the carrier frequency of $1575.42 \mathrm{MHz}$, using the code-division multiple access technique (CDMA) [8].

The main aim of this article is to determine the positioning accuracy of the aircraft Cessna 172 based on the GPS solution. An analysis of the accuracy of the aircraft positioning was carried out based on the actual navigation data from the GPS satellite system, registered by an airborne receiver Topcon HiperPro, mounted in an aircraft Cessna 172. The position of the Cessna 172 was

Kamil Krasuski*, Stepan Savchuk

Institute of Navigation, Military University of Aviation, Deblin, Poland

*E-mail of corresponding author: k.krasuski@law.mil.pl 
determined based on the linear combination IonosphereFree for dual-frequency GPS code observations. The numerical calculations were carried out in individually developed software called Aircraft Positioning Software (APS) Toolbox, developed in the language environment Scilab 6.0.0.

\section{Research method}

The fundamental observation equation of the linear combination Ionosphere-Free, which facilitates the possibility of determining an aircraft position in the GPS satellite system, can be expressed as [9]:

$$
\begin{aligned}
& P_{3}=\alpha_{1} P 1+\alpha_{2} P 2=d+c \cdot(d t r-d t s)+ \\
& +\operatorname{Tr} o p+\operatorname{Re} l+M_{P 3},
\end{aligned}
$$

where:

$P_{3}$ - the "Ionosphere-Free" linear combination for the GPS code observations,

$\left(\alpha_{1}, \alpha_{2}\right)$ - linear coefficients,

$\left(P_{1}, P_{2}\right)$ - code observations at the $1^{\text {st }}$ and $2^{\text {nd }}$ frequency in the GPS system,

$d$ - geometric distance between satellite and receiver, $d=\sqrt{\left(x-X_{S}\right)^{2}+\left(y-Y_{S}\right)^{2}+\left(z-Z_{S}\right)^{2}}$, $(x, y, z)$ - coordinates of the aircraft in XYZ geocentric frame, $\left(X_{S}, Y_{S}, Z_{S}\right)$ - satellite coordinates in GPS system,

$c$ - light speed,

$d t r$ - receiver clock bias correction,

$d t s$ - satellite clock bias correction,

Trop- tropospheric delay,

Re $l$ - relativistic effect,

$M_{P 3}$ - multipath effect for the GPS code observations.

Coordinates of the aircraft from Equation (1) are determined using the least squares method in a stochastic model, as [10]:

$$
\left\{\begin{array}{l}
\mathbf{A} \cdot \mathbf{Q x}-\mathbf{d l}=\mathbf{v} \\
\mathbf{N}=\mathbf{A}^{\mathrm{T}} \cdot \mathbf{p} \cdot \mathbf{A} \\
\mathbf{L}=\mathbf{A}^{\mathrm{T}} \cdot \mathbf{p} \cdot \mathbf{d l} \\
\mathbf{Q x}=\mathbf{N}^{-1} \cdot \mathbf{L}
\end{array},\right.
$$

where:

$\mathbf{Q}_{\mathbf{x}}$ - vector with unknown parameters,

$\mathbf{N}=\mathbf{A}^{\mathrm{T}} \cdot \mathbf{p} \cdot \mathbf{A}$ - matrix of the normal equations frame,

A - matrix of coefficients, matrix is full rank,

p - matrix of weights,

$\mathbf{L}=\mathbf{A}^{\mathrm{T}} \cdot \mathbf{p} \cdot \mathbf{d l}$ - vector of absolute terms,

dl - vector with difference between measurements and modeled parameters,

$\mathbf{v}$ - vector of residuals.

The determined aircraft coordinates from Equations (1) and (2) are physically referenced to the geocentric XYZ frame. Alternatively, there is a possibility to express aircraft coordinates in the ellipsoidal BLh frame. In this case, it is necessary to use a transformation between the geocentric $\mathrm{XYZ}$ frame and the ellipsoidal BLh frame in iterative solution, as shown below [11]:

$$
\begin{aligned}
& B=\arctan \left(\frac{z}{\rho}+\frac{\delta_{1} \cdot \operatorname{tg} B_{i-1}}{\sqrt{\delta_{2} \cdot \operatorname{tg}^{2} B_{i-1}}}\right) \\
& L=\arctan \left(\frac{y}{x}\right) ; h=\frac{\rho}{\cos B}-R,
\end{aligned}
$$

where:

$(a, b)$ - semi-major and semi-minor axes of the ellipsoid frame, respectively,

$e$ - eccentricity, $e=\sqrt{\frac{a^{2}-b^{2}}{a^{2}}}$,

$R$ - radius of curvature of the prime vertical,

$R=\frac{a}{\sqrt{1-e^{2} \cdot \sin ^{2} B}}$,

$\rho=\sqrt{x^{2}+y^{2}}$,

$\delta_{1}=\frac{a \cdot e}{\rho \cdot \sqrt{1-e^{2}}}$,

$\delta_{2}=\frac{1}{1-e^{2}}$,

$i-1$ - previous iteration,

$(B, L, h)$ - geodetic coordinates of aircraft's position,

$B$ - Latitude,

$L$ - Longitude,

$h$ - ellipsoidal height.

\section{Research experiment}

The numerical tests for the presented research method were performed for the actual navigation and GPS observation data, obtained from the airborne Topcon HiperPro receiver, mounted in an aircraft Cessna 172. The test flight by the Cessna 172 was executed over the military airport EPDE, in Dęblin. Duration of the flight was approximately one hour, with the maximum speed of the flight reaching $80 \mathrm{~m} / \mathrm{s}$. The geodetic Topcon HiperPro receiver worked in the kinematic mode, gathering the GPS data at a frequency of $1 \mathrm{~s}$. In order to reduce the effect of multipath interference and radio disturbances, the Topcon HiperPro receiver was installed in the cockpit just behind the plexiglass. The GPS code observations, stored in the memory card of the geodetic receiver Topcon HiperPro, were used to reproduce the position of the aircraft Cessna 172 in the post-processing mode. The numerical calculations to determine the position of the Cessna 172 were made in the authors' original software APS (Aircraft Positioning Software) Toolbox v.1.0.0, which was fully developed in the Scilab 6.0.0. environment. For the purpose of the conducted numerical calculations, the configuration of the APS programme was set, as shown in Table 1.

\section{Results and discussion}

The determined Cessna 172 coordinates in APS programme, in the geocentric XYZ frame and in the ellipsoidal BLh frame, were compared to the actual reference trajectory of the aircraft flight in order to determine the accuracy of the GPS signal in aviation. The precise 
Table 1 Configuration of computations in the APS software

\begin{tabular}{|c|c|}
\hline Parameter & Configuration \\
\hline GNSS system & GPS system \\
\hline type of observations & code observations at the $1^{\text {st }}$ and $2^{\text {nd }}$ frequency in GPS system \\
\hline type of RINEX file & 2.10 \\
\hline source of satellite ephemeris data & precise ephemeris from the IGS service \\
\hline source of satellite clock data & precise ephemeris from the IGS service \\
\hline method of satellite position computation & 9-degrees Lagrange polynomial \\
\hline method of satellite clock bias computation & 9-degrees Lagrange polynomial \\
\hline $\begin{array}{l}\text { effect of Earth rotation and time of pseudorange travelling through } \\
\text { atmosphere }\end{array}$ & applied \\
\hline relativistic effect & applied \\
\hline troposphere source & Simple model \\
\hline receiver clock bias & estimated \\
\hline multipath and measurement noise & not applied \\
\hline satellite and receiver phase center offset & based on ANTEX file from IGS service \\
\hline Sagnac effect & Applied \\
\hline Cut-off elevation & $5^{0}$ \\
\hline a priori standard deviation of pseudorange observations & $1 \mathrm{~m}$ \\
\hline positioning mode & kinematic \\
\hline mathematical model of solution & least square estimation in iterative scheme \\
\hline adjustment processing & Applied \\
\hline maximum number of iterations in a single measurement epoch & $\mathrm{N}=10$ \\
\hline number of unknown parameters & $\mathrm{k}=4$, for each measurement epoch \\
\hline number of observations & $\mathrm{n}>4$, for each measurement epoch \\
\hline interval of computations & $1 \mathrm{~s}$ \\
\hline initial coordinates of aircraft position & based on header of RINEX file \\
\hline time of the GPS system & GPS Time \\
\hline reference frame & IGS'08 \\
\hline format of output coordinates & geocentric XYZ and ellipsoidal BLh \\
\hline local test of residuals & applied \\
\hline global statistical test & test Chi-square \\
\hline significance level & $(1-\alpha=0.95)$ \\
\hline DOP coefficients & estimated \\
\hline coefficients value for HPL and VPL level & $k_{H P L}=6.18$ and $k_{V P L}=5.33$ \\
\hline
\end{tabular}

reference flight trajectory of the Cessna 172 was determined using the PPP precision measurement technique. The PPP measurement technique uses the mathematical model of the linear combination equation - "Ionosphere-Free". The computations of the reference position of the aircraft Cessna 172 for the PPP measurement technique were made in the CSRS-PPP programme [12]. In the framework of the calculations performed in the CSRS-PPP programme, the authors used dual frequency P1/P2 code and L1/L2 phase observations from the airborne receiver Topcon HiperPro. The CSRS-PPP programme uses the IGS precise products such as SP3 precise ephemeris, precise satellite clocks CLK, the characteristics of the antenna phase center of the satellite/receiver ANTEX file format, and DCB hardware delay file format for the computations. The position of the Cessna 172 in the CSRS-PPP programme is expressed in the geocentric XYZ, as well as ellipsoid BLh coordinates, in the global frame IGS'08, whereas the scale of the reference time is the GPS Time. It is worth adding that the program CSRS-PPP allows an accurate determination of kinematic positioning for the aircraft with mean errors of coordinates at a level of approximately $10 \mathrm{~cm} \mathrm{[13].}$

Accuracy of the GPS code positioning for the presented research method in the APS programme was defined both in the geocentric XYZ coordinate frame and in the ellipsoidal BLh frame. The accuracy of the GPS positioning in geocentric XYZ coordinates is specified as [14]: 


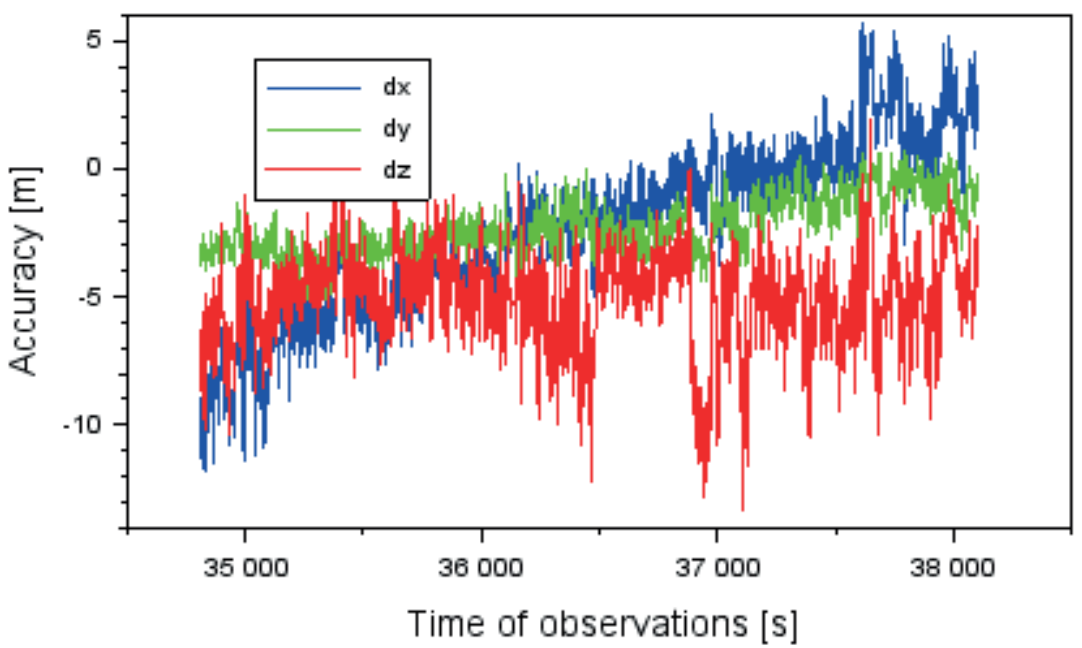

Figure 1 Accuracy of the Cessna 172 aircraft positioning in the XYZ geocentric coordinates

$\left\{\begin{array}{l}d x=x-x_{P P P} \\ d y=y-y_{P P P} \\ d z=z-z_{P P P}\end{array}\right.$

where:

$(d x, d y, d z)$ - accuracy of the GPS positioning in the XYZ geocentric coordinate frame,

$x$ - coordinate of the aircraft along the $\mathrm{X}$ axis, determined based on Equation (1),

$y$ - coordinate of the aircraft along the $\mathrm{Y}$ axis, determined based on Equation (1),

$z$ - coordinate of the aircraft along the $\mathrm{Z}$ axis, determined based on Equation (1),

$x_{P P P}$ - coordinate of the aircraft along the $\mathrm{X}$ axis, determined from the PPP measurement technique in the CSRS-PPP programme,

$y_{P P P}$ - coordinate of the aircraft along the $\mathrm{Y}$ axis, determined from the PPP measurement technique in the CSRS-PPP programme,

$z_{P P P}$ - coordinate of the aircraft along the $\mathrm{Z}$ axis, determined from the PPP measurement technique in the CSRS-PPP programme.

Figure 1 shows results of the GPS positioning accuracy in the geocentric XYZ coordinates for the linear combination "Ionosphere-Free", based on a solution in the APS programme. The positioning accuracy along the $\mathrm{X}$ axis in the GPS system for the receiver Topcon HiperPro ranges from $-11.8 \mathrm{~m}$ to $+5.7 \mathrm{~m}$. In addition, the value of the average positioning accuracy along the $\mathrm{X}$ axis in the GPS system equals $-2.4 \mathrm{~m}$. Moreover, the RMS error along the $\mathrm{X}$ axis is equal to $3.4 \mathrm{~m}$. The positioning accuracy along the $\mathrm{Y}$ axis for the Topcon HiperPro receiver ranges from - $5.2 \mathrm{~m}$ to $+0.9 \mathrm{~m}$. In addition, the value of the average positioning accuracy along the $\mathrm{Y}$ axis in the GPS system is $-2.3 \mathrm{~m}$ Additionally, the RMS error along the $\mathrm{Y}$ axis is equal to $1.1 \mathrm{~m}$. The positioning accuracy along the axis $\mathrm{Z}$ for the Topcon HiperPro receiver ranges from $-13.3 \mathrm{~m}$ to $+2.0 \mathrm{~m}$. Moreover, the value of the average positioning accuracy along the $\mathrm{Z}$ axis in the GPS system is - $5.1 \mathrm{~m}$. Furthermore, the RMS error along the axis $\mathrm{Z}$ is equal to $1.9 \mathrm{~m}$. The span of the GPS positioning accuracy along the $\mathrm{X}$ axis is over 17.5 $\mathrm{m}$, along the $\mathrm{Y}$ axis it is approximately $6 \mathrm{~m}$, and along the $\mathrm{Z}$ axis it is over $15 \mathrm{~m}$. It is worth noting that approximately $75 \%$ of the accuracy of GPS positioning results along the $\mathrm{X}$ axis are less than 0 . On the other hand, approximately $97 \%$ results of the GPS positioning accuracy along the axis $\mathrm{Y}$ is less than 0. Moreover, approximately $99 \%$ results of the GPS positioning accuracy along the axis $\mathrm{Z}$ is less than 0 . It can therefore be concluded that results obtained with regard to accuracy of the GPS positioning in the APS programme are lower than the readings of the aircraft Cessna 172 position in the PPP solutions in the CSRS-PPP programme.

Figure 2 shows another parameter of accuracy of the GPS positioning in the geocentric XYZ frame, in the form of the 3D-error. The 3D-error parameter specifies a shift in coordinates of the aircraft Cessna 172 between a solution in the APS programme and in the CSRS-PPP programme in the geocentric XYZ frame. The mathematical formula specifying the value of the 3D-error parameter can be determined as [15]:

$3 D-$ error $=\sqrt{d x^{2}+d y^{2}+d z^{2}}$.

Based on the obtained results, it is possible to observe that the value of the 3D-error parameter ranges from 1.2 $\mathrm{m}$ to $16.1 \mathrm{~m}$. In addition, the average value of the 3D-error parameter equals $6.9 \mathrm{~m}$. It is worth stressing that the value of the $3 \mathrm{D}$-error parameter towards the end of the observation time decreases to a level below $10 \mathrm{~m}$. The drop in the numerical value of the 3D-error parameter is relevant since it directly translates into the location of the aircraft in the three-dimensional space.

Figure 3 shows results of the GPS positioning accuracy in the ellipsoidal BLh coordinates for the linear combination "Ionosphere-Free" based on a solution in the APS programme. Accuracy of the GPS positioning in the ellipsoidal BLh coordinates is specified as [16]: 


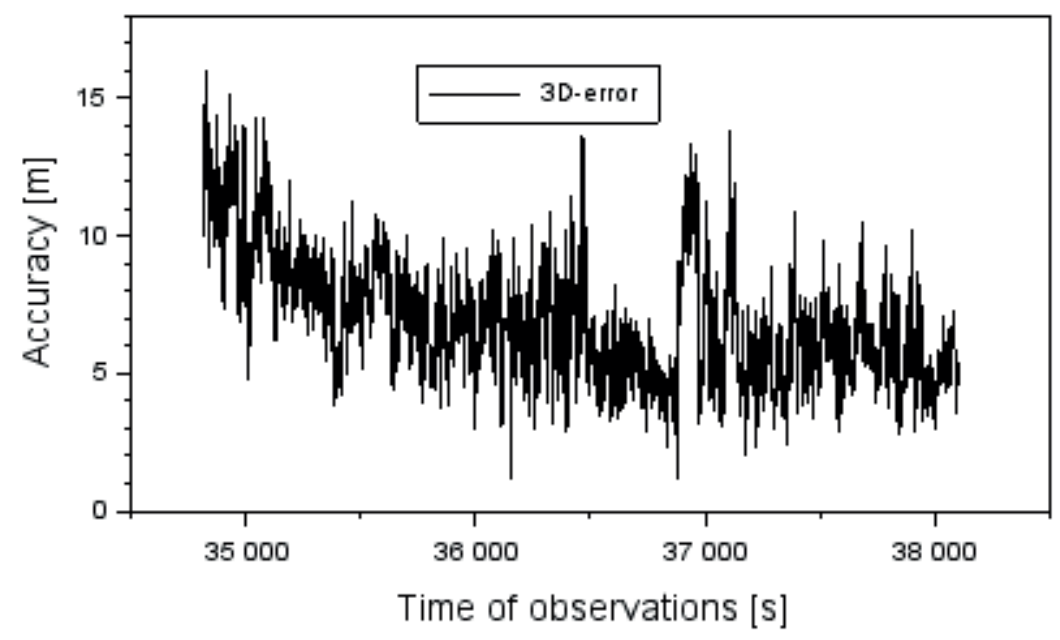

Figure 2 Results of $3 D$-error parameter

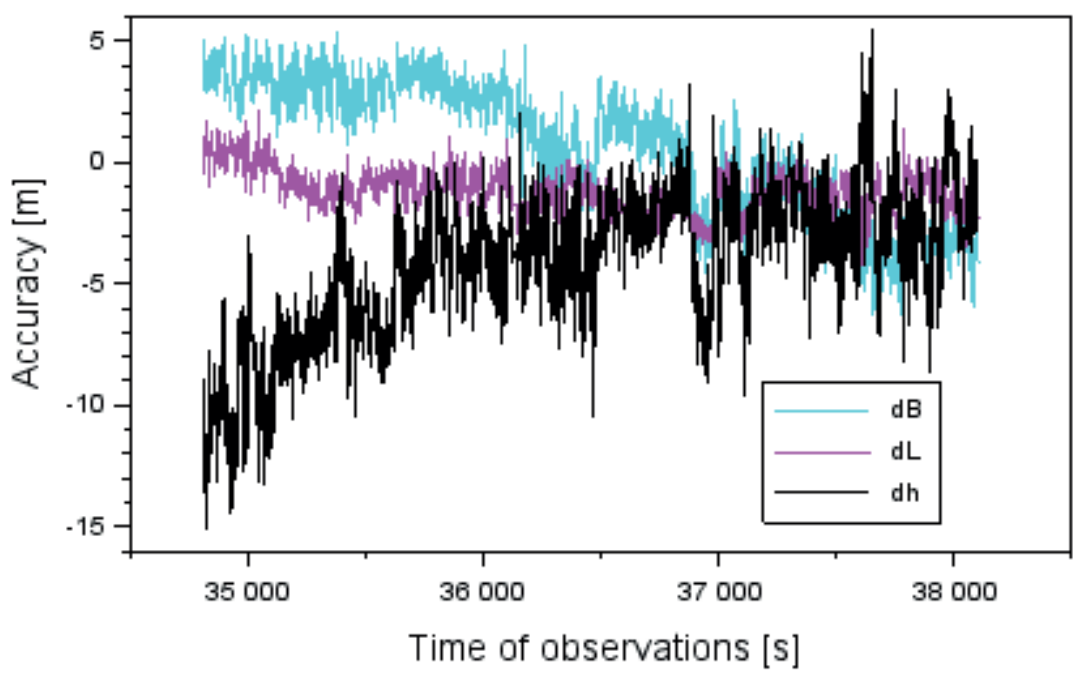

Figure 3 Accuracy of the Cessna 172 aircraft positioning in the BLh ellipsoidal coordinates

$\left\{\begin{array}{l}d B=B-B_{P P P} \\ d L=L-L_{P P P} \\ d h=h-h_{P P P}\end{array}\right.$,

where:

$(d B, d L, d h)$ - accuracy of the GPS positioning in the ellipsoidal BLh frame,

$B$ - coordinate of the aircraft for the B component, determined based on Equation (3),

$L$ - coordinate of the aircraft for the L component, determined based on Equation (3),

$h$ - coordinate of the aircraft for the $\mathrm{h}$ component, determined based on Equation (3),

$B_{P P P}$ - coordinate of the aircraft along the B axis, determined by the PPP measurement technique in the CSRS-PPP programme,

$L_{P P P}$ - coordinate of the aircraft along the $\mathrm{L}$ axis, determined by the PPP measurement technique in the CSRS-PPP programme,

$h_{P P P}$ - coordinate of the aircraft along the $\mathrm{h}$ axis, determined by the PPP measurement technique in the CSRS-PPP programme.
The positioning accuracy for the B component in the GPS system for the receiver Topcon HiperPro ranges from - $6.8 \mathrm{~m}$ to $+5.4 \mathrm{~m}$. In addition, the average value of the positioning accuracy along the axis B in the GPS navigation system is $+0.6 \mathrm{~m}$. Moreover, the RMS error along the axis $\mathrm{B}$ is equal to $2.7 \mathrm{~m}$. The positioning accuracy for the component L, for the receiver Topcon HiperPro, ranges from $-4.2 \mathrm{~m}$ to $+2.2 \mathrm{~m}$. Furthermore, the average value of the positioning accuracy along the axis L in the GPS navigation system equals $-1.2 \mathrm{~m}$. In addition, the RMS error along the axis $\mathrm{L}$ is equal to $0.9 \mathrm{~m}$. The positioning accuracy, for the component $\mathrm{h}$ for the receiver Topcon HiperPro, ranges from $-15.1 \mathrm{~m}$ to $+5.5 \mathrm{~m}$. In addition, the average value of positioning accuracy along the axis $h$ in the GPS navigation system is $-4.1 \mathrm{~m}$. Besides, the RMS error, along the axis $\mathrm{h}$, is equal to $3.1 \mathrm{~m}$. It is worth stressing that only $38 \%$ of the GPS positioning accuracy findings, along the axis $\mathrm{B}$, are below 0 . Therefore, readings of the coordinate $\mathrm{B}$ in the APS programme are inflated in relation to results in the programme CSRS-PPP. On the other hand, approximately $90 \%$ results of the GPS positioning accuracy along the axis L 
are less than 0 . Moreover, approximately $95 \%$ results of the GPS positioning accuracy along the $h$ axis are less than 0 . It can therefore be concluded that the obtained findings with regard to accuracy of the GPS positioning for the $\mathrm{L}$ and $\mathrm{h}$ components in the APS programme are too low in relation to the measurements of the aircraft Cessna 172 in the PPP solution, in the CSRS-PPP programme.

Based on the conducted investigations, it appears that the largest RMS error in the geocentric XYZ coordinates is along the $\mathrm{X}$ axis. On the other hand, the lowest RMS error in the geocentric $\mathrm{XYZ}$ coordinates is along the $\mathrm{Y}$ axis. In the coordinate ellipsoidal BLh frame, the largest RMS error can be observed for the coordinate $\mathrm{h}$, while the lowest one is along the axis $\mathrm{L}$. The value of the RMS parameter results directly from the obtained results in the accuracy of GPS positioning, in the geocentric XYZ frame or in the ellipsoidal BLh frame, respectively. In the case of air operations, it is essential to monitor changes of coordinates of an aircraft flight trajectory, on a continuous basis. Regardless of the selected method (or technique) of the GPS positioning in aviation, the key issue is credibility of the determined aircraft coordinates. Thus, in aviation research conducting an objective control of the navigation parameters recorded by sensors, during the execution of the flight operations, plays a tremendous role. Mounting a GPS receiver on board an aircraft allows monitoring changes in the navigation position, in real time and post factum. For this reason, it is important to develop navigation applications for control calculations of an aircraft position, such as the APS programme, from the beginning.

The presented research method was applied in papers by one of this paper co-authors. For example, in paper [17], the Iono-Free linear combination was utilized for recovery of the aircraft position based on dual-frequency GPS code observation in the APS software. In that paper the parameters such as: aircraft trajectory, receiver clock bias, DOP coefficients, mean errors of aircraft ellipsoidal coordinates, Chi-square statistical test, HPL and VPL integrity terms were presented and described. In the next paper [18], the Iono-Free linear combination was utilized for recovery of the aircraft position based on the dual-frequency GPS code observation in gLAB software package. In that paper, the parameters such as: aircraft trajectory, DOP coefficients, mean errors of aircraft ellipsoidal coordinates, MRSE term, HPL and VPL integrity terms were analyzed and shown. In another article [19], the Iono-Free linear combination for the BSSD module in the APS software package was applied for determination of the aircraft position based on the GPS data. In that paper the parameters such as: DOP coefficients, mean errors of aircraft ellipsoidal and geocentric coordinates, MRSE term, HPL and VPL integrity terms, Chi-square statistical test were estimated and presented.

\section{Conclusions}

The article presents and describes results of the scientific research on use of the dual-frequency GPS code observations in aircraft positioning. In particular, the study focuses on determination of accuracy of the GPS positioning in air transport. During the research, the authors used a linear combination "Ionosphere-Free" as a mathematical model to determine aircraft coordinates. The source materials for the scientific research used the raw P1/P2 code observations in the GPS system from the Topcon HiperPro receiver. The Topcon HiperPro geodetic receiver was installed on board the Cessna 172, which performed a test flight over the EPDE military airport in Dęblin. The collected code P1/P2 observations in the GPS system allowed performing numerical calculations in order to establish coordinates of the Cessna 172. The numerical calculations of the Cessna 172 position were made in the APS v.1.0.0 software programme. For the purpose of determining the GPS positioning accuracy in aviation, the authors made a comparison of the determined coordinates from the APS reference position of the Cessna 172. The precise flight trajectory of the Cessna 172 was determined based on the PPP measurement technique in the CSRS-PPP programme. Based on computations, it was found that the accuracy of the GPS positioning in aviation is:

- $\quad$ between $-13.3 \mathrm{~m}$ and $+5.7 \mathrm{~m}$ in the geocentric XYZ coordinates,

- between $-15.1 \mathrm{~m}$ and $+5.5 \mathrm{~m}$ in the ellipsoidal BLh coordinates.

In addition, the accuracy measurements of determining the position in the form of the RMS parameter are as follows:

- less than $3.4 \mathrm{~m}$ in the geocentric XYZ coordinates,

- less than $3.1 \mathrm{~m}$ in the ellipsoidal BLh coordinates.

The obtained research findings indicate a problem with the low GPS positioning accuracy in aviation. The problem is closely related to the choice of a positioning method presented in this work. The dual-frequency GPS code observations have high measurement noise at the carrier frequency L1 and L2. Moreover, in the case of an application of the dual-frequency GPS code observations in navigation computations, there appears an issue of eliminating an ionospheric delay, which directly affects determination of the horizontal coordinates of an aircraft. The authors plans to conduct research into monitoring the ionospheric status during the air operations in the airspace of Poland. Moreover, in the future additional research is planned aimed at exploiting the GLONASS code observations in aircraft positioning in aviation.

\section{Acknowledgement}

This paper was supported by Military University of Aviation for 2020 year. 


\section{References}

[1] FELLNER, A., JAFERNIK, H., TROMINSKI, P. RNAV GNSS essential for the LUN implementation and the chance for the Polish General Aviation (in Polish). Transactions of the Institute of Aviation. 2011, 211, p. 57-67. ISSN 0509-6669, eISSN 2300-5408.

[2] JAFERNIK, H., KRASUSKI, K. and MICHTA, J. Assessment of suitability of radionavigation devices used in air (in Polish). Scientific Journal of Silesian University of Technology. Series Transport [online]. 2016, 90, p. 99-112. ISSN 0209-3324, eISSN 2450-1549. Available from: https://doi.org/10.20858/sjsutst.2016.90.9

[3] KRZYKOWSKA, K., SIERGIEJCZYK, M. Signal monitoring as a part of maintenance of navigation support system in civil aviation. Archives of Transport System Telematics. 2014, 7(1), p. 36-40. ISSN 1899-8208.

[4] FELLNER, R. Analysis of the EGNOS/GNSS parameters in selected aspects of Polish transport. Transport Problems. 2014, 4(9), p. 27-37. ISSN 1896-0596

[5] JAFERNIK, H., FELLNER, A., MROZIK, M., KRASUSKI, K. Results of aircraft positioning tests in post-processing using GNSS. Scientific Journal of Silesian University of Technology. Series Transport [online]. 2017, 95, p. 67-74. ISSN 0209-3324, eISSN 2450-1549. Available from: https://doi.org/10.20858/sjsutst.2017.95.7

[6] ICAO Standards and Recommended Practices (SARPS). Annex 10, Volume I (Radionavigation aids) International Civil Aviation Organization. 2006, Polish version. Available from: http://www.ulc.gov.pl/pl/prawo/ prawomi\%C4\%99dzynarodowe/206-konwencje, current on: 15.12.2016

[7] GRALL, P., SPECHT, C. Comparative evaluation of GPS SPS standards for accuracy in fixing position (in Polish). Zeszyty Naukowe Akademii Marynarki Wojennej. 2011, 3(186), p. 43-45. ISSN 2657-6260, eISSN 2657-7291.

[8] JANUSZEWSKI, J. Compatibility and interoperability of Satellite Navigation Systems in different modes in transport (in Polish). Prace Naukowe Politechniki Warszawskiej. 2013, 95, p. 199-208. ISSN 1230-9265.

[9] GAO, Y., CHEN, K. Performance analysis of precise point positioning using real-time orbit and clock products. Journal of Global Positioning System [online]. 2004, 3(1-2), p. 95-100. eISSN 1446-3164. Available from: https://doi.org/10.5081/ jgps.3.1.95

[10] SANZ SUBIRANA, J., JUAN ZORNOZA J. M., HERNANDEZ-PAJARES M. Fundamentals and algorithms. Vol. 1. In: GNSS data processing. Noordwijk, Netherlands: ESTEC, ESA Communications, 2013. ISBN 978-92-9221-886-7, p. 139144.

[11] OSADA, E. Geodesy (in Polish). Wroclaw: Oficyna Wydawnicza Politechniki Wroclawskiej, 2001. ISBN 83-7085-663-2, p. 236-241.

[12] MALINOWSKI, M., KWIECIEN, J. A comparative study of precise point positioning (PPP) accuracy using online services. Reports on Geodesy and Geoinformatics [online]. 2016, 102(1), p. 15-31. ISSN 2391-8152. Available from: http://dx.doi.org/10.1515/rgg-2016-0025

[13] KRASUSKI, K. Utilization CSRS-PPP software for recovery aircraft's position. Scientific Journal of Silesian University of Technology. Series Transport [online]. 2015, 89, p. 61-68. ISSN 0209-3324, eISSN 2450-1549. Available from: https://doi.org/10.20858/sjsutst.2015.89.7

[14] BAKULA, M. Static code DGPS positioning based on three reference stations. Geodesy and Cartography. 2005, 54(2), p. 81-92. ISSN 1648-3502.

[15] RODRIGUEZ-BILBAO, I., RADICELLA, S. M., RODRIGUEZ-CADEROT, G., HERRAIZ, M. Precise point positioning performance in the presence of the 28 October 2003 sudden increase in total electron content. Space Weather [online]. 2015, 13, p. 698-708. eISSN 1542-7390. Available from: https://doi.org/10.1002/2015SW001201

[16] SWIATEK, A., JAWORSKI, L. and TOMASIK, L. EGNOS Monitoring prepared in space research centre P.A.S. for SPMS project. Artificial Satellites [online]. 2017, 52(4), p. 109-120. ISSN 2083-6104. Available from: https://doi.org/10.1515/ arsa-2017-0010

[17] KRASUSKI, K. Application of PPP-KINEMATIC method and aircraft positioning software for calculation of plane's position, Przeglad Techniczny Uzbrojenia. 2016, 140(4), p. 53-68. ISSN 1230-3801.

[18] KRASUSKI, K., JAFERNIK, H. Implementation GNSS satellite technique in air transport - example (in Polish). In: Characteristics of selected research aspects in theory and practice. Katowice: Wydawnictwo Naukowe Sophia, 2017. ISBN 978-83-65357-91-5, p. 21-31.

[19] CWIKLAK, J., GRZEGORZEWSKI, M., KRASUSKI, K. The application of the BSSD iono-free linear combination method in the processing of aircraft positioning, Journal of KONES Powertrain and Transport [online]. 2019, 26(3), p. 15-22. ISSN 2354-0133. Available from: https://doi.org/10.2478/kones-2019-0052 


\section{Annex - Nomenclature}

\begin{tabular}{|c|c|}
\hline The abbreviation & The full name \\
\hline GLONASS & Globalnaja Nawigacionnaja Sputnikowaja Sistiema / Global Navigation Satellite System \\
\hline GPS & Global Positioning System \\
\hline BSSD & Between Satellite Single Difference \\
\hline ICAO & International Civil Aviation Organization \\
\hline GNSS & Global Navigation Satellite System \\
\hline ABAS & Aircraft Based Augmentation System \\
\hline SBAS & Satellite Based Augmentation System \\
\hline GBAS & Ground Based Augmentation System \\
\hline EPDE & ICAO airport code \\
\hline APS & Aircraft Positioning Software \\
\hline IGS & International GNSS Service \\
\hline ANTEX & Antenna Exchange Format \\
\hline RINEX & Receiver Independent Exchange System \\
\hline HPL & Horizontal Protection Level \\
\hline VPL & Vertical Protection Level \\
\hline DOP & Dilution of Precision \\
\hline MRSE & Mean Radial Spherical Error \\
\hline PPP & Precise Point Positioning \\
\hline $\mathrm{XYZ}$ & Geocentric coordinates \\
\hline BLh & Latitude, Longitude, ellipsoidal height \\
\hline BeiDou & Chinese satellite navigation system \\
\hline Galileo & European satellite navigation system \\
\hline QZSS Zenith & Japanese regional satellite navigation system \\
\hline EGNOS & European Geostationary Navigation Overlay Service \\
\hline SDCM & The System for Differential Corrections and Monitoring \\
\hline WAAS & The Wide Area Augmentation System \\
\hline MSAS & The Multi-functional Satellite Augmentation System \\
\hline GAGAN & The GPS Aided Geo Augmented Navigation \\
\hline NAVIC & Indian Regional Navigational Satellite System \\
\hline SPS & Standard Positioning Service \\
\hline $\mathrm{C} / \mathrm{A}$ & Coarse Acquisition \\
\hline CDMA & Code-Division Multiple Acces \\
\hline CSRS-PPP & Canadian Spatial Reference System - Precise Point Positioning \\
\hline DCB & Differential Code Biases \\
\hline RMS & Root Mean Square \\
\hline
\end{tabular}

